\title{
PRETENDENTES À ADOÇÃO: MOTIVAÇÕES E AVALIAÇÃO DE UM CURSO PREPARATÓ- RIO*
}

\author{
CATULA DA LUZ PELISOLI \\ TRIBUNAL DE JUSTIÇA DO ESTADO DO RIO GRANDE DO \\ SUL \\ PASSO FUNDO, RIO GRANDE DO SUL, BRASIL \\ CATULAPELISOLI@YAHOO.COM.BR \\ ADRIANE PEREIRA LEITE \\ TRIBUNAL DE JUSTIÇA DO ESTADO DO RIO GRANDE DO \\ SUL \\ PASSO FUNDO, RIO GRANDE DO SUL, BRASIL \\ ADRILEITE@TJRS.JUS.BR \\ PATRICIA OLIVEIRA ROMERO \\ TRIBUNAL DE JUSTIÇA DO ESTADO DO RIO GRANDE DO \\ SUL \\ PASSO FUNDO, RIO GRANDE DO SUL, BRASIL \\ PROMERO@TJRS.JUS.BR
}

\footnotetext{
* Este trabalho não possui financiamento para pesquisa. As autoras agradecem ao Tribunal de Justiça do Estado do Rio Grande do Sul - TJ/RS, à Universidade de Passo Fundo - UPF, à Secretaria Municipal de Assistência Social - Semcas de Passo Fundo e ao Grupo de Apoio à Adoção - Adotchê.
} 


\section{PRETENDENTES À ADOÇÃO: MOTIVAÇÕES E AVALIAÇÃO DE UM CURSO PREPARATÓRIO}

Resumo: Uma análise de fichas de avaliação de um curso preparatório para adoção, preenchidas por 123 pessoas requerentes em processos de habilitação, indicou flexibilização no perfil da criança desejada, com uma ampliação da faixa etária, porém ainda distante da realidade das crianças disponíveis para adoção. A preparação psicossocial foi avaliada positivamente, configurando-se como um importante momento da habilitação para adoção.

Palavras-chave: Adoção, Preparação psicossocial, Psicologia jurídica, Serviço Social.

\section{CANDIDATOS A ADOPCIÓN: MOTIVACIONES Y EVALUACIÓN DE UN CURSO PREPARATORIO}

Resumen: Una análisis de formas de evaluación de un curso preparatorio para adopción, completado por 123 personas que solicitan procesos de calificación, indicado flexibilidad en el perfil del niño deseado, con una expansión del rango de edad, pero aún lejos de la realidad de los niños disponibles para adopción. La etapa de preparación psicosocial se evaluó positivamente, lo que representa un momento importante de calificación para la adopción Palabras Clave: Adopción, preparación psicosocial, psicología jurídica, trabajo social.

\section{CANDIDATES TO ADOPTION: MOTIVATIONS AND EVALUATION OF A PREPARATORY COURSE}

Abstract: The analysis of evaluation sheets of a preparatory course for adoption, completed by 123 people that were in the process of qualifying for adoption, indicated a flexibility in the profile of the desired child, with a widening of the age group, but it is still far from the reality of the children available. The psychosocial preparation stage was evaluated positively and it is configured as an important moment of the habilitation for adoption. Keywords: Adoption, Psychosocial preparation, Forensic Psychology, Social Service.

\section{INTRODUÇÃO}

Em 2021, mais de quatro mil crianças e adolescentes possuem seus nomes no Sistema Nacional de Adoção - SNA e aguardam a colocação em uma família substituta no Brasil (CONSELHO NACIONAL DE JUSTIÇA - CNJ, 2021). A maior parte dessa população é do sexo masculino (54\%) e muitas dessas crianças e adolescentes possuem irmãos que também aguardam o mesmo 
destino (52\%). Em torno de 13\% das crianças possuem entre zero e três anos de idade e $63 \%$ já passaram dos 9 anos, fatores conhecidos por tornarem mais difícil a inserção nas famílias que aguardam a adoção. Grande parte das pessoas cadastradas e habilitadas para adoção está disponível para adotar apenas uma criança e não aceita a colocação de irmãos (62\%). Além disso, 85,6\% dos pretendentes desejam uma criança de até seis anos de idade, enquanto apenas $24 \%$ das crianças estão nessa faixa etária (CNJ, 2021). As diferenças entre os desejos dos habilitados e a realidade das crianças institucionalizadas é considerado um grande desafio da adoção no Brasil (PELISOLI; OLIVEIRA JUNIOR, 2016).

A adoção é considerada medida excepcional, pois a convivência com a família de origem deve ser prioritária, segundo o Estatuto da Criança e do Adolescente (BRASIL, 1990). Antes dessa medida, portanto, são feitas diversas tentativas de manutenção da criança com seus familiares biológicos, seja por meio de estratégias de assistência social, tratamentos de saúde e outros encaminhamentos feitos diretamente aos genitores, seja por meio da colocação da criança na família extensa. Será quando essas alternativas não forem suficientemente protetivas que a criança será acolhida institucionalmente ou em uma família acolhedora, e posteriormente, será colocada em família substituta, sendo finalmente adotada. Para essa medida excepcional ocorrer, os responsáveis legais devem entregar a criança ou o Poder Judiciário destituirá o poder familiar dos responsáveis legais sobre ela. A criança estará juridicamente disponível para a adoção quando uma dessas duas situações estiver definida (consentimento ou destituição) (BRASIL, 1990; 2009).

Situações de entrega da criança acontecem geralmente quando existe uma família extensa enfraquecida, falta de apoio familiar, ausência de companheiro, condições socioeconômicas desfavorecidas e o fato de a criança ser fruto de um relacionamento fortuito (FRESTON; FRESTON, 1994; OLIVEIRA, 2002). A maioria das genitoras que entrega seus filhos é jovem (até 30 anos), solteira, pobre, com baixa escolaridade e procedente de regiões pobres (GHESTI; CAMPOS; SILVEIRA, 2000). O fato de o pai biológico não assumir a paternidade é um dos motivos para que a mãe biológica decida pela entrega do filho (WEBER, 1999). Uma análise de processos que tramitaram no Juizado da Infância e Juventude numa comarca do Rio Grande do Sul constatou que as mulheres que entregaram seus filhos pertenciam às camadas socialmente desfavorecidas, eram solteiras e jovens; não tinham 
apoio familiar nem do genitor e sua motivação para a entrega da criança a ausência de condições socioeconômicas, a impossibilidade de criar um filho fruto de uma violência sexual ou de relação eventual (LEÃO ET AL., 2014). Já com relação à destituição do poder familiar, o Código Civil afirma que pode ocorrer em situações em que os pais castigaram imoderadamente o filho, abandonaram ou praticaram atos contrários à moral e aos bons costumes. Os motivos do afastamento compulsório da família natural e extensa e a institucionalização das crianças envolvem negligência, abandono, falta temporária de condições, questões muitas vezes associadas à dificuldade financeira da família (SERRANO, 2011).

A adoção legal de crianças como praticada no Brasil nos dias de hoje foi construída a partir do Estatuto da Criança e do Adolescente e alterações dessa lei (BRASIL, 1990; 2009). A habilitação para a adoção inicia com um processo judicial em que os interessados precisam comprovar identidade, renda, ocupação, estado civil, residência, além de atestar sua idoneidade moral, por meio de certidões negativas cíveis e criminais, bem como seu estado de saúde através de atestados médicos. A aptidão psicossocial é outro requisito desse processo, e ela é verificada por meio de avaliações sociais e psicológicas, realizadas pelas equipes interdisciplinares presentes nos Juizados da Infância e Juventude. Esses procedimentos técnicos avaliam: capacidade para exercer papel de pai/mãe, capacidade para satisfazer as necessidades do adotado em suas fases de desenvolvimento, situação socioeconômica, personalidade e maturidade, relacionamentos familiares e sociais, qualidade do relacionamento conjugal, disponibilidade afetiva, habilidade de resolver problemas, flexibilidade (PILOTTI, 1988). A história pregressa dos candidatos, suas motivações, o significado da adoção em suas vidas, como a família extensa percebe o projeto de adoção, sentimentos para abordar a origem da criança, expectativas em relação ao filho, equilíbrio, condições de exercer a parentalidade e de manter projetos pessoais, estabilidade e estrutura psíquica e emocional dos integrantes da família, experiências familiares e de vida, crenças e expectativas com relação ao filho a ser adotado e compreensão de aspectos relacionados à adoção e à história anterior do adotado também são investigados durante a avaliação psicossocial (CHAVES, SILVA, FRIZZO, 2020; HOPPE et al, 1992).

Antes ou após a avaliação psicossocial, devem os habilitados participar de um curso preparatório. A chamada preparação psicossocial não apresenta um padrão único, podendo ter cargas horárias e formatos diferentes. 
Ela deve, porém, ter a finalidade de propiciar aos requerentes um espaço de conhecimento, de trocas e de vivências e de funcionar como uma preparação reflexiva para a parentalidade adotiva (CHAVES, 2002). Os cursos podem envolver aspectos sobre a importância da revelação da adoção ao filho, expressão de empatia, compreensão e respeito às necessidades da criança, comunicação com o filho (SANZ, 1997), maior conhecimento sobre as próprias emoções, apoio à aceitação das diferenças, aspectos sobre a educação da criança/adolescente (AMORÓS, 1987), compreensão das dificuldades que podem ocorrer, exploração da natureza da parentalidade, reconhecimento de suas capacidades, auto avaliação de suas motivações, habilidades e necessidades (BINIÉS, 1997).

$\mathrm{Na}$ comarca em que se procedeu o presente estudo, no interior do Rio Grande do Sul, o curso preparatório ocorre com duas cargas horárias possíveis, sendo em oito ou nove horas. Os mesmos conteúdos são abordados, independentemente da carga horária disponibilizada, em seis momentos: 1) aspectos jurídicos da adoção; 2) aspectos sociais da adoção; 3 ) aspectos pedagógicos da adoção; 4) aspectos psicológicos da adoção; 5) realidade das crianças institucionalizadas no município e 6) experiências de adoção. Os primeiros quatro momentos são coordenados por professoras universitárias com ampla experiência no tema. A realidade das crianças é trazida por membros das equipes técnicas das casas de acolhimento da cidade, ligados à Assistência Social da Prefeitura local. Por fim, as experiências de adoção são trazidas por membros do grupo de apoio à adoção que realiza encontros mensais regulares para habilitados e adotantes. O curso costuma ser oferecido após os candidatos terem realizado a avaliação psicossocial. As turmas variam entre 20 e 40 pessoas (10 a 20 processos), em virtude da disponibilidade de salas e do tempo de espera da turma para a realização do curso. A prioridade é de que sejam realizados encontros com grupos menores (até 20 pessoas ou 10 processos), para que se possibilite a discussão e se tenha uma maior abertura para o diálogo e troca de conhecimentos e experiências entre os participantes. Com a pandemia da Covid-19, os encontros passaram a ser virtuais, mas continuaram abordando os mesmos temas, carga horária e contando com os mesmos profissionais.

Nos últimos anos, o Tribunal de Justiça do Estado do Rio Grande do Sul elaborou e enviou às comarcas o Projeto Primeiro Passo, que buscou trazer parâmetros mais específicos para todo o Estado sobre como proceder a preparação psicossocial para os candidatos à adoção. Observou-se que a 
proposta oferecida na comarca já estava em consonância com as diretrizes oferecidas pelo Tribunal, inclusive contando com avaliações prévias e posteriores ao curso. Foram feitas poucas alterações para a adequação ao projeto. O Projeto Primeiro Passo orienta que as turmas devem ter no máximo 20 participantes, no mínimo 4 horas de duração, e os encontros devem contar com abordagens expositivas, vídeos, relatos de experiências, dinâmicas de grupo ou estudos de caso (TRIBUNAL DE JUSTIÇA DO ESTADO DO RIO GRANDE DO SUL, 2017).

\section{Método}

Participantes: As fichas de avaliação analisadas referem-se à 123 pessoas dos sexos masculino e feminino residentes no interior do Estado do Rio Grande do Sul e requerentes de 68 processos judiciais de habilitação para adoção num Juizado da Infância e Juventude. A maior parte desses requerentes é formada por casais $(81 \% ; n=55)$ em busca da inserção de seus nomes no Sistema Nacional de Adoção - SNA e a menor parte formada por pessoas solteiras (19\%; $n=13$ ) com este mesmo objetivo, sendo apenas um homem. Outros dados sobre os requerentes serão melhor apresentados na seção de resultados.

Instrumentos: Foi utilizada uma Ficha de Avaliação especificamente desenvolvida para ser respondida antes e depois do curso preparatório para pretendentes à adoção numa comarca do interior do Estado do Rio Grande do Sul. A ficha apresenta questões sobre idade dos pretendentes e perfil da criança desejada (dados quantitativos) e motivação para adoção, opiniões sobre a adoção tardia (antes e depois do curso), expectativas sobre o curso e avaliação ao final do evento (dados qualitativos). Os dados foram coletados em edições do curso que ocorreram entre os anos de 2014 e 2017.

Procedimentos: Os requerentes responderam à parte inicial da ficha de avaliação antes do curso (perfil do pretendente e da criança desejada, motivação para adoção, opinião prévia sobre adoção tardia e expectativas sobre o curso) e o restante das questões após o encerramento do evento (opinião sobre adoção tardia e avaliação do curso, com possibilidade de críticas e sugestões). Essa avaliação tem sido regularmente realizada na comarca para fins de análise do curso preparatório. Para essa pesquisa, as fichas foram inseridas em um banco de dados, sem as identificações individuais, para a realização das análises quantitativa e qualitativa. As variáveis quantitativas foram analisadas com o uso do SPSS 20.0, observando especialmente medi- 
das de tendência central e desvios padrão (estatística descritiva). Já as variáveis qualitativas foram submetidas à análise de conteúdo (BARDIN, 2011), realizada por uma das pesquisadoras, com ampla experiência em pesquisa qualitativa, e revisada por duas juízas independentes. Procedimentos mistos permitem a apreensão do fenômeno e do objeto de estudo por prismas distintos (CÂMARA, 2013).

Considerações éticas: Os requerentes foram informados sobre os objetivos do estudo, sendo eles convidados a responderem ao instrumento de forma voluntária. As informações compuseram um banco de dados com avaliações do curso preparatório, para fins de planejamento e pesquisa. O Juiz da Infância e Juventude da Comarca responsável pelo curso preparatório autorizou o uso científico das informações, desde que preservadas as identidades dos participantes. Considerando que se trata de "pesquisa realizada com base de dados, cujas informações são agregadas, sem possibilidade de identificação individual", dispensa-se o registro e avaliação por Comitê de Ética (CONSELHO NACIONAL DE SAÚDE, 2016). Ainda assim, foram observadas as diretrizes éticas da pesquisa envolvendo seres humanos, considerando os princípios da autonomia, não maleficência, beneficência, justiça e equidade (BRASIL, 2012).

\section{Resultados e Discussão}

Dados quantitativos: Foram analisados dados de requerentes de 68 processos judiciais de habilitação para adoção, sendo que 55 desses processos contavam com dois requerentes e 13 com apenas um requerente, totalizando 123 pessoas. Dentre estes, $73,5 \%$ eram requerentes que formavam casais heterossexuais ( $n=50$ processos); $6 \%$ formavam casais homoafetivos $(n=4$ processos); $17,6 \%$ eram de autoras solteiras ( $n=12$ processos) e 1,5\% de autores solteiros ( $\mathrm{n}=1$ processo). As idades dos requerentes variaram de 25 a 62 anos $(M=39,6$ anos; $D P=7,5)$. Desses, 69,1\% ( $n=47$ processos) participaram de uma turma reduzida do curso preparatório, que era composta por até 20 pessoas. A turma reduzida ocorreu em sala com menor espaço, em círculo, com a ideia de propiciar discussões mais próximas e maior abertura entre participantes e professoras convidadas. O restante, $30,9 \%$ ( $n=21$ processos) participou de uma turma ampliada, que envolveu em torno de 40 pessoas e ocorreu em sala de auditório. Os temas e assuntos foram idênticos nas duas turmas, porém, a turma reduzida participou de três encontros entre gh e 12h, divididos em três semanas (carga horária $=9$ horas), enquanto a turma 
ampliada participou de dois turnos, um entre gh e $12 \mathrm{~h}$ e outro entre $13 \mathrm{~h}$ e 18h (carga horária = 8 horas), sofrendo uma redução de uma hora de carga horária.

A maior parte dos pretendentes não faz restrições ao sexo da criança, colocando como "indiferente" sua opção em $70,6 \%$ dos processos $(n=48)$. Os requerentes desejam uma criança do sexo feminino em $23,5 \%$ dos casos ( $n=16$ processos) e do sexo masculino em $5,9 \%$ dos casos ( $n=4$ processos). $57,4 \%$ ( $n=31$ processos) dos habilitandos desejavam uma criança entre zero e três anos de idade. Considerados casos de adoção tardia, a adoção de crianças com mais de três anos foi indicada como possibilidade por pessoas requerentes em 23 processos (42,6\%), sendo esses distribuídos da seguinte maneira:

Tabela 1: Idade máxima da criança desejada (adoção tardia)

\begin{tabular}{|l|l|}
\hline \multicolumn{1}{|c|}{ Idade máxima da criança desejada } & \multicolumn{1}{c|}{ Número de processos (n) } \\
\hline 3 anos e meio & 1 \\
\hline 4 anos & 7 \\
\hline 5 anos & 6 \\
\hline 6 anos & 7 \\
\hline 7 anos & 1 \\
\hline 10 anos & 1 \\
\hline
\end{tabular}

O desequilíbrio entre os interesses dos pretendentes e as características das crianças e adolescentes que aguardam a adoção é um problema conhecido no país (CNJ, 2021). Na comarca estudada, o maior percentual de requerentes deseja uma criança até três anos de idade. Apesar de observar-se no presente estudo um percentual significativo de requerentes que estão dispostos à adoção tardia, percebe-se que com o aumento da idade da criança, há visível redução do número de candidatos à adoção.

No que diz respeito à cor da criança, observa-se a seguinte distribuição:

Tabela 2: Cor da criança desejada

\begin{tabular}{|l|l|l|}
\hline \multicolumn{1}{|c|}{ Cor da criança desejada } & Número de processos (n) & \multicolumn{1}{c|}{ Percentual } \\
\hline Indiferente & 35 & $51,5 \%$ \\
\hline Branca & 15 & $22,1 \%$ \\
\hline Branca e parda & 12 & $17,6 \%$ \\
\hline
\end{tabular}




\begin{tabular}{|l|l|l|}
\hline Parda & 2 & $2,9 \%$ \\
\hline Branca, negra e parda & 2 & $2,9 \%$ \\
\hline Branca, parda e amarela & 1 & $1,5 \%$ \\
\hline
\end{tabular}

Quanto à análise da cor da criança desejada, observa-se que apenas 2,9\% da amostra indicou aceitar crianças negras. Apesar de o Rio Grande do Sul não ter tantas crianças negras em acolhimento institucional, chama a atenção o fato de ainda os pais adotivos desejarem crianças que sejam de certa forma semelhantes fisicamente com eles, reproduzindo uma lógica da maternidade e paternidade biológica.

Uma última variável quantitativa analisada foi a resposta a escalas de auto avaliação respondida pelos participantes. Os requerentes avaliavam numa escala de zero a dez quanto se sentiam preparados para a adoção antes e depois do curso. A média para a auto avaliação antes do curso foi de 8,04 pontos ( $D P=2,1)$ e para depois do curso foi de $8,61(D P=2,2)$. Análise estatística demonstrou diferenças significativas no resultado antes e depois do curso $(t=-2,55 ; d f=58 ; p<0,05)$. Compreende-se esse resultado como positivo, no sentido de que em geral, quando as pessoas entram com o processo de adoção, já passaram por vários momentos de pensar, refletir, discutir com seu companheiro/familiares e/ou buscar informações em vários meios, sentindo-se naquele momento capaz. Ainda assim, o curso fez diferença para que os requerentes se sentissem ainda mais preparados para o exercício da paternidade e da maternidade.

Dados qualitativos: A Tabela 3 apresenta os resultados referentes à questão sobre a motivação para a adoção dos pretendentes. A partir da análise de conteúdo, emergiram três categorias de respostas: 1) Completar a família; 2) Infertilidade e 3) Solidariedade. As categorias de análise foram apresentadas na ordem de frequência de resposta.

A maior parte dos participantes entende que a adoção propiciará o exercício da maternidade e da paternidade, possibilitando assim a constituição de uma família. Observa-se que a presença de filhos, de acordo com os participantes, é que transforma a vida do casal numa vida familiar. O vínculo entre pais e filhos é visto como "incondicional", e dando "sentido à existência".

A infertilidade é o segundo principal motivo para as pessoas buscarem a adoção como alternativa para o desejo de exercer o papel parental. Outra 
categoria de resposta foi a solidariedade, quando os participantes indicam que a opção pela adoção se deu no sentido de oportunizar à criança uma família. Em alguns casos, a solidariedade aparece associada às outras categorias, e em outros casos, ela aparece isolada, quando o participante indica a solidariedade como motivação única para a adoção.

Tabela 3: Motivação para adoção

\begin{tabular}{|c|c|c|}
\hline Questão & Categorias de análise & Exemplos \\
\hline $\begin{array}{l}\text { Motivação } \\
\text { para adoção }\end{array}$ & Completar a família & $\begin{array}{l}\text { "Para completar minha } \\
\text { família, para um lar mais } \\
\text { feliz e completo"; "Exerc- } \\
\text { er a maternidade e a pa- } \\
\text { ternidade, construir uma } \\
\text { família"; "Compartilhar } \\
\text { emoções e amor"; "Para dar } \\
\text { amor e consequentemente } \\
\text { ser amada. Criar/construir } \\
\text { um vínculo incondicional. } \\
\text { Para passar bons valores"; } \\
\text { "Compartilhar a vida com } \\
\text { o filho encontrando um } \\
\text { sentido maior à própria } \\
\text { existência"; "Vontade de } \\
\text { ser mãe, criar, educar, amar, } \\
\text { orientar" }\end{array}$ \\
\hline $\begin{array}{l}\text { Motivação } \\
\text { para adoção }\end{array}$ & Infertilidade & $\begin{array}{l}\text { "Não conseguimos pelos } \\
\text { métodos naturais"; "Pela } \\
\text { impossibilidade de termos } \\
\text { filhos biológicos" }\end{array}$ \\
\hline $\begin{array}{l}\text { Motivação } \\
\text { para adoção }\end{array}$ & Solidariedade & $\begin{array}{l}\text { "Fazer nosso papel de ci- } \\
\text { dadão perante a sociedade, } \\
\text { oferecendo um futuro mel- } \\
\text { hor para crianças."; "Opor- } \\
\text { tunidade para a criança ter } \\
\text { uma família"; "Para que } \\
\text { mais uma criança tenha um } \\
\text { lar com amor e cuidado que } \\
\text { todos precisam"; "Propor- } \\
\text { cionar uma família, edu- } \\
\text { cação, saúde" }\end{array}$ \\
\hline
\end{tabular}

A literatura indica que infertilidade e altruísmo são as principais razões pelas quais as pessoas decidem pela adoção (WEBER, 2003). Algumas pessoas adotam porque não conseguiram ter filhos biológicos e compreendem 
que será a partir da adoção que buscarão satisfazer o desejo de ser pai/mãe (WEBER, 2011). Compaixão, empatia e desejo de contribuir também são motivações indicadas por pessoas que buscam a adoção. O desejo de exercer a maternidade/paternidade, necessidade de preencher a solidão, proporcionar companhia a um filho único, escolher o sexo do próximo filho, substituir um filho falecido são outros motivos alegados por pretendentes à adoção (COSTA; CAMPOS, 2003).

A adoção tardia é assim considerada quando a criança tem idade mais avançada. Segundo Ebrahim (2001), quem adota crianças com mais de três anos possui um perfil diferente, em geral, de quem adota bebês: possuem mais idade, nem todos são casados, muitas vezes já possuem filhos biológicos, possuem um nível de escolaridade mais alto, renda familiar mais alta, além de serem mais maduros e mais estáveis emocionalmente. Uma das questões respondidas pelos participantes do curso foi justamente a opinião desses futuros pais sobre a adoção tardia, coletada antes e depois do curso preparatório. Antes do curso, os participantes associavam prioritariamente à adoção tardia à questão da dificuldade de adaptação de crianças mais velhas aos lares adotivos. Alguns indicavam também a impossibilidade de, ao adotar uma criança mais velha ou adolescente, acompanhar o desenvolvimento integral, incluindo as diversas fases. Os pretendentes ainda associaram a adoção tardia a um ato de amor e de ajuda ao próximo, indicando assim que a adoção tardia estaria ligada mais fortemente à questão da caridade e solidariedade do que a adoção de crianças menores e bebês. A Tabela 4 apresenta os resultados das opiniões sobre o tema, antes e depois do curso. 
Tabela 4: Opiniões sobre a adoção tardia antes e depois do curso

\begin{tabular}{|l|l|l|}
\hline Adoção tardia & Dificuldade de adaptação & $\begin{array}{l}\text { "Receio. A criança já vem } \\
\text { com uma bagagem, person- } \\
\text { alidade formada e de difícil } \\
\text { entendimento." } \\
\text { "Pensamos não estar prepa- } \\
\text { rados para acolher um ado- } \\
\text { lescente"; "Acho bom, mas } \\
\text { não me sinto preparada"; "É } \\
\text { uma adoção que exige mais } \\
\text { de ambas as partes"; "Medo } \\
\text { da criança não se adaptar"; } \\
\text { "Achamos que seria difícil a } \\
\text { adaptação da criança e da } \\
\text { família"; "Pode ser feita des- } \\
\text { de que com um acompan- } \\
\text { hamento mais profundo"; } \\
\text { "Vemos que temos que ter } \\
\text { uma preparação psicológica } \\
\text { para dar o suporte que esta } \\
\text { criança precisa"; "A principal } \\
\text { preocupação é a história } \\
\text { passada que teve com outra } \\
\text { família e o receio de não } \\
\text { saber lidar com isso"; "Desa- } \\
\text { fiador" }\end{array}$ \\
\hline
\end{tabular}




\begin{tabular}{|c|c|c|}
\hline Adoção tardia & Ato de amor & $\begin{array}{l}\text { "Ato bonito de ajudar o } \\
\text { próximo"; "Um ato de } \\
\text { amor" } \\
\text { "Algo que ajuda a superar } \\
\text { medos e traumas, por meio } \\
\text { de amor, carinho, atenção } \\
\text { dos pais adotivos"; "Acho } \\
\text { que nunca é tarde para re- } \\
\text { alizarmos sonhos. A criança, } \\
\text { independente da idade, } \\
\text { merece um lar, uma família"; } \\
\text { "Acho lindo quem adota"; } \\
\text { "Excelente para quem tem } \\
\text { esse perfil"; "Sou a favor, } \\
\text { pois o ser humano é um } \\
\text { eterno processo"; "Nunca } \\
\text { é tarde para entrar em uma } \\
\text { família, para se construir } \\
\text { uma família. Acreditamos } \\
\text { que o amor transforma"; "É } \\
\text { benéfica para as crianças, } \\
\text { cuidado aprendizagem, } \\
\text { família, proteção" }\end{array}$ \\
\hline Adoção tardia & $\begin{array}{l}\text { Impossibilidade de acom- } \\
\text { panhar o desenvolvimento } \\
\text { integral da criança }\end{array}$ & $\begin{array}{l}\text { "Não possibilita viver todos } \\
\text { os passos da criança"; "Não } \\
\text { podemos acompanhar o } \\
\text { crescimento dela"; "Meu } \\
\text { desejo é de um bebê para } \\
\text { acompanhar e conseguir } \\
\text { passar por todas as fases do } \\
\text { desenvolvimento" }\end{array}$ \\
\hline $\begin{array}{l}\text { Opiniões sobre adoção } \\
\text { tardia após o curso }\end{array}$ & Não mudou opinião & $\begin{array}{l}\text { "É maravilhosa e impor- } \\
\text { tante, mas gostaríamos de } \\
\text { passar por todo o processo"; } \\
\text { "Bem interessante, entre- } \\
\text { tanto, nos interessa ainda } \\
\text { bebês"; "O pensamento con- } \\
\text { tinua o mesmo. Mantemos } \\
\text { o perfil do início do curso"; } \\
\text { "Continuo pensando que a } \\
\text { adoção tardia não está nos } \\
\text { meus planos. Quero viven- } \\
\text { ciar toda a parte da criança } \\
\text { bebê" }\end{array}$ \\
\hline
\end{tabular}




\begin{tabular}{|c|c|c|}
\hline $\begin{array}{l}\text { Opiniões sobre adoção } \\
\text { tardia após o curso }\end{array}$ & $\begin{array}{l}\text { Flexibilizou o pensamento } \\
\text { sobre a adoção tardia }\end{array}$ & $\begin{array}{l}\text { "Passei a considerar a ideia } \\
\text { da adoção tardia"; "Uma } \\
\text { possibilidade"; "Acredita- } \\
\text { mos que a adaptação será } \\
\text { mais fácil do que imagináva- } \\
\text { mos, e que dependerá mais } \\
\text { de nós do que da criança"; } \\
\text { "Achamos que é possível, } \\
\text { desde que trabalhados os } \\
\text { aspectos psicológicos, emo- } \\
\text { cionais e sociais"; "Reaval- } \\
\text { iando a possibilidade"; "Nos } \\
\text { fez refletir ainda mais sobre } \\
\text { o assunto"; "Percebi que } \\
\text { não existe muita diferença e } \\
\text { as pessoas têm todo o apoio } \\
\text { possível para lidar com a } \\
\text { adoção"; "Que indepen- } \\
\text { dente de ser bebê ou uma } \\
\text { criança mais velha, ou até } \\
\text { mesmo biológico, não é por } \\
\text { ser adoção tardia que a cri- } \\
\text { ança vai dar problema"; "Os } \\
\text { filhos biológicos também po- } \\
\text { dem apresentar problemas" }\end{array}$ \\
\hline $\begin{array}{l}\text { Opiniões sobre adoção } \\
\text { tardia após o curso }\end{array}$ & $\begin{array}{l}\text { É necessário mais tempo } \\
\text { para reflexão }\end{array}$ & $\begin{array}{l}\text { "Talvez com o futuro com } \\
\text { mais conhecimento possa vir } \\
\text { a mudar de ideia"; "Ainda } \\
\text { me sinto insegura"; "Ainda } \\
\text { pensamos que precisa ser } \\
\text { dialogado e mais pensado"; } \\
\text { "Iremos avaliar de agora } \\
\text { em diante"; "Gerou uma } \\
\text { possibilidade e um interesse } \\
\text { na adoção tardia, mas com } \\
\text { receios"; "Merece maior } \\
\text { conscientização por parte } \\
\text { dos pretendentes" }\end{array}$ \\
\hline
\end{tabular}

Observa-se que o curso possibilitou a alguns pretendentes refletirem sobre o tema. Ainda que não tenha alterado as opiniões de todos, é possível afirmar que houve flexibilização em relação a isso, e uma abertura para pensar sobre o tema. Albuquerque, Souza e Silva (2019) identificaram que os postulantes à adoção apresentam representações sociais sobre adoção tardia ancoradas em crenças relacionadas à formação da personalidade, à bagagem familiar e à institucionalização das crianças e adolescentes aptos 
à adoção. Os autores encontraram que os candidatos demonstram preferência pela adoção convencional (nesse estudo considerada até dois anos de idade) em detrimento da adoção tardia, baseados em concepções "tradicionais" de maternidade, nas facilidades em se adotar uma criança com menos idade, além da possibilidade de modelar seus comportamentos. Também referem que os postulantes associam a adoção tardia a possíveis dificuldades em se criar um adolescente em razão de sua bagagem familiar, sua personalidade formada, e seu período de institucionalização. Peixoto e colaboradores (2019, no entanto, indicam que estratégias como auxílio psicológico familiar, busca por atendimento médico especializado, apoio da família extensa, paciência, reforço positivo sobre a adoção e persistência dos pais para superar as dificuldades contribuíram para o êxito dessas adoções.

A Tabela 5 apresenta os resultados referentes às expectativas e à avaliação final do curso. Os candidatos referiram diversas questões que entendem que devem ser abordadas num curso preparatório, especialmente aquelas que envolvem questões psicológicas e jurídicas. Dentre as psicológicas, incluem-se orientações sobre o desenvolvimento das crianças, e sobre como contar e abordar a adoção com a criança. Dentre as jurídicas, é demandado um maior conhecimento sobre as etapas processuais. Foram ainda demandadas as questões de ordem social, educacional e trocas de experiências. Observa-se que o curso, de modo geral, satisfez as expectativas dos pretendentes, que fizeram avaliações muito positivas a respeito dos conteúdos e das profissionais responsáveis. Ainda assim, fizeram algumas sugestões, como abordar a possibilidade de pessoas solteiras poderem entrar com processo de habilitação, fenômeno cada vez mais comum, mas ainda incipiente na nossa sociedade.

Tabela 5: Expectativas e avaliação final do curso preparatório 


\begin{tabular}{|c|c|c|}
\hline $\begin{array}{c}\text { Expectativa } \\
\text { em relação ao curso } \\
\text { (assuntos a serem aborda- } \\
\text { dos) }\end{array}$ & Aspectos psicológicos & $\begin{array}{l}\text { "Aspectos emocionais"; } \\
\text { "Orientar como agir com a } \\
\text { criança"; "Entender o que } \\
\text { se passa na cabeça de uma } \\
\text { criança ou adolescente aban- } \\
\text { donado"; "Como contar } \\
\text { sobre a adoção para o filho"; } \\
\text { "História da criança, como } \\
\text { devo agir com a criança no } \\
\text { decorrer do processo"; "A } \\
\text { inclusão da criança no novo } \\
\text { lar"; "De como se preparar } \\
\text { para receber a criança"; } \\
\text { "Adaptação da criança e dos } \\
\text { pretendentes ao convívio } \\
\text { familiar"; "Como melhor } \\
\text { exercer a paternidade"; } \\
\text { "Como lidar com o psicológi- } \\
\text { co dos participantes, com a } \\
\text { espera"; "Fortalecimento da } \\
\text { decisão de adotar"; "Assun- } \\
\text { tos sobre a criança, idades } \\
\text { e cuidados"; "Nos orientar } \\
\text { quanto à responsabilidade e } \\
\text { seriedade desse processo"; } \\
\text { "Como se comportar, como } \\
\text { lidar com certas situações"; } \\
\text { "Amadurecimento" }\end{array}$ \\
\hline $\begin{array}{c}\text { Expectativa } \\
\text { em relação ao curso } \\
\text { (assuntos a serem aborda- } \\
\text { dos) }\end{array}$ & Aspectos jurídicos & $\begin{array}{l}\text { "Lei, como encarar o proces- } \\
\text { so da adoção"; "Burocracia } \\
\text { e tempo de espera, etapas } \\
\text { da adoção"; "Entender mel- } \\
\text { hor como vai ser o proces- } \\
\text { so"; "Cadastro (onde inicia } \\
\text { o processo de adoção"; } \\
\text { "Regras da adoção" }\end{array}$ \\
\hline $\begin{array}{c}\text { Expectativa } \\
\text { em relação ao curso } \\
\text { (assuntos a serem aborda- } \\
\text { dos) }\end{array}$ & $\begin{array}{l}\text { Aspectos sociais e educa- } \\
\text { cionais }\end{array}$ & $\begin{array}{l}\text { "Realidade das crianças a } \\
\text { serem adotadas"; "Situação } \\
\text { da adoção na cidade. O perfil } \\
\text { das crianças disponíveis para } \\
\text { adoção"; "Conhecer como } \\
\text { funciona a vida das crianças } \\
\text { abandonadas"; "Quantas } \\
\text { crianças estão nas casas de } \\
\text { acolhimento"; "Educação"; } \\
\text { "Assuntos pedagógicos" }\end{array}$ \\
\hline
\end{tabular}




\begin{tabular}{|c|c|c|}
\hline $\begin{array}{c}\text { Expectativa } \\
\text { em relação ao curso } \\
\text { (assuntos a serem aborda- } \\
\text { dos) }\end{array}$ & Troca de experiências & $\begin{array}{l}\text { "Troca de experiências e } \\
\text { relatos de famílias que adot- } \\
\text { aram"; "Casos reais" }\end{array}$ \\
\hline Avaliação do curso & Avaliações positivas & $\begin{array}{l}\text { "Aprendizado muito inter- } \\
\text { essante"; "O curso foi ótimo } \\
\text { e muito esclarecedor. Me } \\
\text { ajudou muito"; "O curso } \\
\text { foi maravilhoso. Nos deixou } \\
\text { com mais expectativa, mais } \\
\text { desejos e aumentou nosso } \\
\text { amor."; "Foram ótimos } \\
\text { diálogos e esclarecimentos } \\
\text { de coisa que não sabíamos"; } \\
\text { "Esclareceu muitas dúvidas. } \\
\text { Reforçamos nossa decisão } \\
\text { quanto à adoção"; "Foi bem } \\
\text { explicado e teve bastante } \\
\text { participação"; Superou } \\
\text { todas as minhas expectati- } \\
\text { vas. Me senti acolhida, com } \\
\text { liberdade de fazer perguntas } \\
\text { e tirar as dúvidas"; "Está } \\
\text { bem estruturado"; "Achei o } \\
\text { curso extremamente infor- } \\
\text { mativo e me sinto muito } \\
\text { mais segura para seguir } \\
\text { com esse processo"; "Muito } \\
\text { bom. Ele me ajudou a tirar } \\
\text { dúvidas, medos e mitos."; } \\
\text { "Adoramos fazer o curso, } \\
\text { nos ensinou, nos ajudou e } \\
\text { orientou muito, nos ampliou } \\
\text { a visão sobre adoção"; "Os } \\
\text { encontros foram muito } \\
\text { agradáveis"; "Ficamos satis- } \\
\text { feitos com a programação e } \\
\text { com a qualidade dos profis- } \\
\text { sionais que ministraram o } \\
\text { curso" }\end{array}$ \\
\hline
\end{tabular}




\begin{tabular}{|l|l|l|}
\hline Avaliação do curso & Sugestões e críticas & $\begin{array}{l}\text { Mais tempo com o Grupo de } \\
\text { apoio à adoção"; "Abordar } \\
\text { a espera e ter mais depoi- } \\
\text { mentos no curso"; "Acho } \\
\text { que poderíamos ter mais } \\
\text { casos de exemplos"; "Sugiro } \\
\text { que a parte social e jurídi- } \\
\text { ca abordada no primeiro } \\
\text { encontro tenha mais espaço } \\
\text { nos próximos cursos"; Divul- } \\
\text { gar a ideia de que pessoas } \\
\text { solteiras podem entrar com } \\
\text { processo de adoção"; "Ter } \\
\text { um pouco mais de tempo" } \\
\text { "O curso poderia ser antes } \\
\text { da entrevista pois supre } \\
\text { várias dúvidas" }\end{array}$ \\
\hline
\end{tabular}

\section{CONSIDERAÇÕES FINAIS}

A adoção é ainda buscada como projeto de completude da família, mesmo que as concepções contemporâneas sobre a instituição familiar sejam hoje ampliadas e compreendam suas diferentes configurações. A presença de filhos e o exercício da maternidade e da paternidade ainda possuem muito significado e relevância no contexto social contemporâneo. A adoção é buscada, em grande parte dos casos, por casais heterossexuais que não conseguiram ter filhos biológicos em razão de infertilidade. Mas mulheres solteiras, homens solteiros e casais homoafetivos também tem feito e concretizado o projeto de serem mães e pais por meio da adoção de crianças e adolescentes. A solidariedade também tem sua função motivadora nesse projeto de vida e muitos candidatos à adoção referem que desejam proporcionar educação, saúde e amor para uma criança.

O desejo de vivenciar todas as etapas do desenvolvimento da criança e os receios de receberem uma criança ou adolescente com vivências e aprendizagens diferentes das suas são razões dadas pelos candidatos que demonstram o desejo pela adoção de crianças de até três anos de idade. Muitos candidatos não se sentem capazes nem preparados para lidar com uma adaptação mais complexa da criança, possuem receios e preocupações. Idealizam a adoção tardia como um "ato de amor" ou de "ajuda ao 
próximo", mas grande parte a distancia de suas realidades e possibilidades. O curso preparatório aborda a questão da adoção tardia, no sentido de trazer a realidade das crianças e adolescentes institucionalizadas e sensibilizar os candidatos para essa situação social. A desmistificação da adoção tardia e a abordagem desse assunto no curso tem tido efeitos positivos em direção a uma flexibilização das faixas etárias da criança desejada. Ainda que essa flexibilização não seja suficiente para que ocorram mudanças significativas na realidade do acolhimento institucional, tem havido um movimento de reflexão nesse sentido.

O curso preparatório não deve ter a intenção de impor a adoção tardia como opção aos adotantes, mas permite uma reflexão sobre essa realidade, assim como possibilita que os candidatos conheçam de forma mais consistente os trâmites processuais e a legislação nacional, e discutam sobre práticas em relação ao futuro filho ou filha. A questão da escolaridade e aprendizagem, do processo de adaptação nos momentos iniciais da chegada da criança/adolescente, o nome e a revelação da história da origem para a criança são abordados nessa etapa de preparação psicossocial, assim como outros temas importantes. Considerando que a carga horária disponibilizada, ainda que seja maior do que a carga horária mínima recomendada pelo Tribunal de Justiça do Estado do Rio Grande do Sul, é insuficiente para toda a complexidade desse processo de tornar-se pai e mãe adotivos, a proximidade entre a equipe da preparação psicossocial com o grupo de apoio à adoção busca fortalecer esses relacionamentos. A intenção é a de que os candidatos permaneçam em contato com o tema da adoção por meio do grupo de apoio.

A avaliação de programas de preparação psicossocial e de seus efeitos sobre os candidatos e sobre a adoção de crianças é uma necessidade no Brasil. Há lacunas importantes na literatura nacional sobre o tema, o que dificulta o planejamento e intervenções baseadas em evidências. Ainda existem histórias de crianças “devolvidas” e adaptações mal sucedidas. Diferentes fatores estão envolvidos nessas situações, mas a preparação psicossocial pode contribuir para um maior conhecimento da realidade pelos candidatos, para a troca de experiências e para a articulação entre as equipes que trabalham na adoção e os grupos de apoio. O fortalecimento dessas relações e uma abordagem de preparação que possa considerar dados empíricos podem fazer diferença positiva na adoção de crianças e adolescentes no Brasil. 
CADERNOS DE COMUNICAÇÃO

UNIVERSIDADE FEDERAL DE SANTA MARIA

\section{REFERÊNCIAS}

ALBUQUERQUE, L. A. F. P.; SOUZA, A. X. A.; SILVA, J. Representações Sociais Elaboradas por Postulantes sobre Adoção Convencional e Adoção Tardia. Rev. Psicol. IMED, Passo Fundo, v. 11, n. 2, p. 15-33, dez. 2019.

AMORÓS, P. La adopción y el acogimiento familiar. Madrid: Narcea S.A. de Ediciones, 1987.

BARDIN, L. Análise de conteúdo. São Paulo: Edições 70, 2011.

BINIÉS, P. Quién puede ser padre adoptivo? Critérios de selectión. Infancia y Adoptión, v.2, p.11-20, 1997.

BRASIL. Lei 8069/1990. Dispõe sobre o Estatuto da criança e do adolescente. Brasília: Governo Federal, 1990.

BRASIL. Lei 12010/2009. Dispõe sobre adoção. Brasília: Governo Federal, 2009.

BRASIL. Resolução 466, de 12 de dezembro de 2012. Aprova diretrizes e normas regulamentadoras de pesquisas envolvendo seres humanos. Governo Federal: Ministério da Saúde, 2012.

CÂMARA, R. H. Análise de conteúdo: da teoria à prática em pesquisas sociais aplicadas às organizações. Gerais: Revista Interinstitucional de Psicologia, v.6, n. 2, p. 179-191, 2013.

CHAVES, V. P. A interação mãe-criança em famílias adotivas: Um estudo comparativo. Dissertação de Mestrado. Universidade Federal do Rio Grande do Sul, 2002.

CHAVES, V. P., SILVA, P. S., FRIZZO, G. B. Avaliação para habilitação para adoção. Em C. S. HUTZ, D. R. BANDEIRA, C. M. TRENTINI, S. L. R. ROVINSKI \& V. M. LAGO. Avaliação psicológica no contexto forense. Porto Alegre: Artmed, 2020.

CONSELHO NACIONAL DE JUSTIÇA. Relatório estatístico nacional do Sistema nacional de adoção e acolhimento - SNA, 2021. Disponível em https://www.cnj.jus.br/programas-e-acoes/adocao/ Acesso em 15 de julho de 2021.

CONSELHO NACIONAL DE SAÚDE. Resolução 510 de 07 de abril de 2016. Diário Oficial da União - DOU, 98, 1, 44-46, 2016.

COSTA, L. F.; CAMPOS, N. M. V. A avaliação psicossocial no contexto da adoção: vivências das famílias adotantes. Psicologia: Teoria e Pesquisa, v.19, n.3, p. 221-230, 2003.

EBRAHIM, S. G. Adoção tardia: Altruísmo, maturidade e estabilidade emocional. Psicologia: Reflexão e Crítica, v. 14, n.1, p.73-80, 2001.

FRESTON, Y. M. B.; FRESTON, P. A mãe biológica em casos de adoção: Um perfil da pobreza e do abandono. Em F. FREIRE (Ed.). Abandono e adoção. Contribuições para uma cultura da adoção II, p. 81-90. Curitiba, PR: Terra dos Homens, 1994.

GHESTO, I.; CAMPOS, N.; SILVEIRA, M.C. Perfil da Adoção no DF. Trabalho apresentado no I Congresso Psicossocial Jurídico do TJDFT, Brasília-DF, 2000.

HOPPE, M.; Equipe Técnica do Juizado da Infância e da Juventude de Porto Alegre . Estatuto passado a limpo. Juizado da Infância e da Juventude de Porto Alegre, 1992.

LEAO, F. E. et al. Mulheres que entregam seus filhos para adoção: um estudo documental. 
Rev. Subj., Fortaleza, v. 14, n. 2, p. 276-283, ago. 2014.

OLIVEIRA, N. G. S. Padrões de adoção: Reinterpretação à luz da perspectiva etológica. Tese de Doutorado não-publicada, Instituto de Psicologia, Universidade de São Paulo, SP, 2002.

PEIXOTO, A. C. et al. Desafios e estratégias implementadas na adoção de crianças maiores e adolescentes. Nova perspect. sist., São Paulo, v. 28, n. 63, p. 89-108, abr. 2019.

PELISOLI, C.; OLIVEIRA-JÚNIOR, D. F. Aspectos psicossociais e jurídicos da adoção de crianças e adolescentes no Brasil. Em P. I. C. GOMIDE \& S. S. STAUT JÚNIOR. Introdução à psicologia forense. Curitiba, PR: Juruá, 2016.

PILOTTI, F. Manual de procedimentos para a formação da família adotiva. Montevidéu: Instituto Interamericano da Criança, 1988.

SANZ, F. G. La intervencion psicológica em las propuestas de adopción internacional. Uma reflexion desde la práctica. Apuntes de Psicología, n. 49-50, p. 201-208, 1997.

SERRANO, S. A. Quem são as crianças institucionalizadas e suas famílias? Refletindo sobre os indicadores de abrigamento. Em M. C. ROSSETI-FERREIRA; S. A. SERRANO \& I. G. ALMEIDA (Orgs.). $O$ acolhimento institucional na perspectiva da criança, p. 86-118. São Paulo: Hucitec, 2011.

TRIBUNAL DE JUSTIÇA DO ESTADO DO RIO GRANDE DO SUL. Projeto Primeiro Passo. Coordenadoria da Infância e da Juventude, Porto Alegre, Rio Grande do Sul, 2017.

WEBER, L. N. D. Aspectos psicológicos da adoção. Curitiba: Juruá, 1999.

WEBER, L. N. D. Pais e filhos por adoção no Brasil. Características, expectativas e sentimentos. Curitiba, PR: Juruá, 2003.

WEBER, L. N. D. O psicólogo e as práticas de adoção. Em H. S. GONÇALVES \& E. P. BRANDÃO. Psicologia jurídica no Brasil. $3^{\text {a }}$ ed. Rio de Janeiro: Nau, 2011. 


\section{Catula da Luz Pelisoli}

Graduação em Psicologia (UNISINOS, 2005), Especialização em Psicoterapia Cognitivo Comportamental (WP - Centro de Psicoterapia Cognitivo Comportamental, 2009), Especialização em Psicologia Clínica (Conselho Federal de Psicologia, 2017), Mestrado (UFRGS, 2008) e Doutorado (UFRGS, 2013) em Psicologia, com período de doutorado sanduíche na University of Hawaii at Hilo; Pós Doutorado (UFRGS, 2019). Atualmente, é Psicóloga Judiciária do Tribunal de Justiça do Estado do Rio Grande do Sul na Comarca de Passo Fundo, Professora convidada em cursos de extensão, formação e especialização; Supervisora na área de depoimento especial e documentos psicológicos para fins judiciais. Membro do Núcleo de Estudos e Pesquisas em Adolescência - NEPA UFRGS. E-mail: catulapelisoli@yahoo.com.br

\section{Adriane Pereira Leite}

Assistente social judiciária.

E-mail: adrileite@tjrs.jus.br

\section{Patricia Oliveira Romero}

Psicóloga judiciária.

E-mail:promero@tjrs.jus.br 